\title{
Presynaptic Modulation of Spontaneous Inhibitory Postsynaptic Currents by Gamma-hydroxybutyrate in the Substantia Nigra Pars Compacta
}

\author{
Alfredo Brancucci ${ }^{1,2}$, Nicola Berretta ${ }^{2}$, Nicola B Mercuri ${ }^{2,3}$ and Walter Francesconi*, 1,4 \\ 'Dipartimento di Fisiologia e Biochimica 'G Moruzzi', Università di Pisa; Pisa, Italy; ${ }^{2}$ Fondazione S Lucia IRCCS, Roma, Italy; ${ }^{3}$ Clinica Neurologica, \\ Università di Tor Vergata; Roma, Italy; ${ }^{4}$ Department of Neuropharmacology, The Scripps Research Institute, La Jolla, CA, USA
}

\begin{abstract}
The regulation of GABA release from the inhibitory input to dopamine cells in the substantia nigra pars compacta (SNc) plays a key role in different reward-related behaviors. Gamma-hydroxybutyrate (GHB) has therapeutical properties in various psychiatric disorders, especially in alcohol abuse. GHB is also used as a drug of abuse, which induces sedation and euphoria. Using whole-cell patch-clamp recordings, we studied the effects of GHB on GABA release in the SNc by recording spontaneous inhibitory postsynaptic currents (sIPSCs) in brain slices of 21 - to 25-day-old rats. We found that GHB depressed the frequency and amplitude of sIPSCs, while the frequency and the amplitude of miniature inhibitory postsynaptic currents (mIPSCs), recorded in the presence of TTX, were not affected. However, in the presence of high extracellular potassium $(15 \mathrm{mM})$, which increases the contribution of voltage-dependent calcium channels, GHB induced a reduction in the frequency of the mIPSCs without any effect on their amplitude. All of these effects were $\mathrm{GABA}_{\mathrm{B}}$-independent and they were blocked by the GHB receptor antagonist NCS-382. The present results indicate that GHB inhibits spontaneous inhibitory synaptic transmission recorded from dopaminergic neurons in the SNc likely by reducing voltage-dependent calcium influx involved in presynaptic GABA release.

Neuropsychopharmacology (2004) 29, 537-543, advance online publication, 5 November 2003; doi:I 0. I038/sj.npp. I 300344
\end{abstract}

Keywords: Gamma-hydroxybutyric acid (GHB); dopaminergic neurons; substantia nigra pars compacta (SNc); spontaneous inhibitory postsynaptic currents (sIPSCs); NCS-382; voltage-dependent calcium influx

\section{INTRODUCTION}

Gamma-hydroxybutyrate (GHB) is a naturally occurring compound of the mammalian brain (Bessman and Fishbein, 1963; Roth and Giarman, 1969). Although the physiological function of GHB has not been clearly defined, the existence of binding sites as well as mechanisms for synthesis, release, and uptake in the brain indicate that GHB acts as neuromodulator on specific neuronal populations (Maitre, 1997). High-affinity binding site studies revealed a G protein-coupled GHB receptor (Snead, 2000) present mainly in the cortex, hippocampus, dopaminergic areas of the midbrain such as the substantia nigra, and the striatum (Benavides et al, 1982; Hechler et al, 1987, 1992; Castelli et al, 2000). GHB reportedly possesses several neurophar-

\footnotetext{
*Correspondence: W Francesconi, Department of Neuropharmacology, The Scripps Research Institute, 10550 North Torrey Pines Road, La Jolla, CA 92037, USA, Tel: + I 858784 7322, Fax: + I 858784 7393, E-mail:wfranc@scripps.edu

Received 01 April 2003; revised 30 September 2003; accepted 03 October 2003

Online publication: 6 October 2003 at http://www.acnp.org/citations/ Npp I0060303/38/default.pdf
}

macological properties such as reduction of voluntary alcohol intake in rats (Fadda et al, 1988) and humans (Addolorato et al, 1998), treatment of several psychiatric (Poldrugo and Addolorato, 1999) and sleep disorders (Mamelak et al, 1986), and efficacy as an anesthetic agent (Kleinschmidt et al, 1999). Recently, GHB has become a popular drug of abuse due to its ability to induce euphoria, hallucinations, sedation, and relaxation (Galloway et al, 1997; Bernasconi et al, 1999). GHB, like many other drugs of abuse, induces a modulation of dopamine release in the nigrostriatal and mesocorticolimbic system (Hechler et al, 1991; Hedou et al, 2000). Furthermore, electrophysiological studies revealed that GHB modulates the spontaneous firing rate and suppresses burst activity of nigral neurons (Diana et al, 1991; Nissbrandt et al, 1994; Madden and Johnson, 1998).

The substantia nigra pars compacta $(\mathrm{SNc})$ is located in the midbrain and contains the cell bodies of dopaminergic and GABAergic neurons. Dopaminergic neurons give rise to diffuse mesolimbic and nigrostriatal projections, which play an important role in the actions of many drugs of abuse. Dopaminergic projections are involved in addiction by controlling reward effects of psychoactive substances and 
by generating compulsive drug-seeking behaviors (Hyman and Malenka, 2001; Maharajan et al, 2001; Fasano and Brambilla, 2002). The great majority of synapses on the dopaminergic neurons of the SNc are GABAergic (Bolam and Smith, 1990). These inhibitory inputs arise from local interneurons as well as from other areas such as globus pallidus, striatum, and substantia nigra pars reticulata (Somogyi et al, 1981; Smith and Bolam, 1990; Smith et al, 1996; Chen and Rice, 2002). GABA exerts its action on dopaminergic neurons of the $\mathrm{SNc}$ through $\mathrm{GABA}_{\mathrm{A}}$ and $\mathrm{GABA}_{\mathrm{B}}$ receptors (Bunney et al, 1991; Hausser and Yung, 1994; Paladini et al, 1999).

GHB has been shown to reduce GABA-mediated synaptic transmission in different brain systems (Cammalleri et al, 2002; Xie and Smart, 1992b; Hu et al, 2000). However, regulation by $\mathrm{GHB}$ of GABA release in the $\mathrm{SNc}$ has not been investigated and could be important in shaping the pattern of activity of dopamine neurons. The goal of the present study was to determine the acute actions of GHB on spontaneous GABA-mediated synaptic transmission in the $\mathrm{SNc}$ as revealed by whole-cell patch-clamp recordings of spontaneous inhibitory postsynaptic currents (sIPSCs) from dopaminergic neurons.

\section{METHODS}

\section{Slice Preparation}

Experiments were performed on horizontal slices of the rat ventral midbrain containing the substantia nigra pars compacta, obtained as described previously (Mercuri et al, 1995). Briefly, male Wistar rats (P21-P25, 60-80 g) were anesthetized with intraperitoneal ketamine injection and decapitated. The brain was rapidly removed from the skull and horizontal slices $\left(250 \mu \mathrm{m}\right.$ thick) were cut in $8-12^{\circ} \mathrm{C}$ artificial cerebrospinal fluid solution (ACSF) using a vibratome. After $1 \mathrm{~h}$ incubation in $34^{\circ} \mathrm{C}$ ACSF, containing (in mM) $126 \mathrm{NaCl}, 2.5 \mathrm{KCl}, 1.2 \mathrm{MgCl}_{2}, 1.2 \mathrm{NaH}_{2} \mathrm{PO}_{4}, 2.4$ $\mathrm{CaCl}_{2}, 10$ glucose, $19 \mathrm{NaHCO}_{3}$ and gassed with $95 \% \mathrm{O}_{2}-5 \%$ $\mathrm{CO}_{2}$, a single slice was transferred to a recording chamber. Here the slice was completely submerged in continuously flowing $(2.5 \mathrm{ml} / \mathrm{min})$ ACSF $\left(33-34^{\circ} \mathrm{C}, \mathrm{pH} 7.4\right)$ and immobilized with a platinum grid. The chamber was mounted on the stage of an upright microscope Axioskop (Carl Zeiss, Oberkochen, Germany) equipped for infrared video microscopy (Hamamatsu, Hamamatsu City, Japan).

\section{Whole-cell Recordings}

sIPSCs were recorded in the whole-cell configuration of the patch-clamp technique (voltage-clamp mode) with an Axopatch 200B amplifier (Axon Instruments; Foster City, $\mathrm{CA})$, at a holding potential of $-60 \mathrm{mV}$. Patch electrodes, pulled with a PP-83 Narishige puller (Tokyo, Japan) using $1.5 \mathrm{~mm}$ borosilicate glass, had a resistance of 3-6 M $\Omega$ when filled with an intracellular solution containing (in $\mathrm{mM}$ ) 130 $\mathrm{KCl}, 2 \mathrm{MgCl}_{2}, 1 \mathrm{CaCl}_{2}, 1 \mathrm{NaCl}, 11$ EGTA, 10 HEPES, $2 \mathrm{Mg}$ ATP, $0.3 \mathrm{Na}_{3}$-GTP; pH was adjusted to 7.3 with $\mathrm{KOH}$. Individual neurons within the $\mathrm{SNc}$ were visualized by infrared video imaging and approached by applying positive pressure in the electrode. Dopaminergic neurons were recognized on the basis of the presence of a large hyperpolarization-induced inward current, which is typical in these cells (Grace and Bunney, 1983; Mercuri et al, 1995). Series resistance and whole-cell capacitance were monitored continuously during the experiment and recordings were discarded if series resistance changed by more than $20 \%$ from control conditions.

\section{Drugs}

Drugs were dissolved in ACSF and applied in the bath by changing the superfusion solution to one that differed only in its content of $\operatorname{drug}(\mathrm{s})$. The ratio of flow rate to bath volume ensured complete exchange within $1 \mathrm{~min}$. Drugs used were GHB, 3-N[1-(s)-(3,4-dichlorophenyl) ethyl] amino-2(s)-hydroxypropyl-p-benzyl-phosphinic acid (CGP $55845 \mathrm{~A}$ ) and 6,7,8,9-tetrahydro-5(-) $[\mathrm{H}]$-benzocycloheptene5-ol-4-ylidene acetic acid (NCS-382) from Laboratorio Farmaceutico CT (SanRemo, Italy), tetrodotoxin (TTX) from Alomone Labs, and bicuculline from Sigma.

\section{Data Analysis}

Recordings were digitized online with the p-Clamp 7 software (Axon Instruments) using a Digidata 1200 acquisition board (Axon Instruments). Spontaneous events were analyzed with the MiniAnalysis software (Synaptosoft Inc., Decatur, GA). The data were presented as mean \pm standard error of the mean (SEM). Statistical differences were determined on raw data by repeated measures analysis of variance (ANOVA) and Kolmogorov-Smirnov test at a significance level of 0.05 .

\section{RESULTS}

We recorded from 52 dopaminergic neurons within the SNc. Dopaminergic cells were identified by their prominent hyperpolarization-activated inward current (Grace and Bunney, 1983; Mercuri et al, 1995). Neurons had a mean input resistance of $110 \pm 15 \mathrm{M} \Omega$, which was not statistically affected by GHB $(106 \pm 19 \mathrm{M} \Omega, p=0.48)$.

\section{Effects of GHB on sIPSCs}

Spontaneous synaptic currents were recorded from $\mathrm{SNc}$ dopaminergic neurons in the presence of the $\mathrm{GABA}_{\mathrm{B}}$ antagonist CGP 55845A $(1 \mu \mathrm{M})$ to prevent the effects of GHB on the $\mathrm{GABA}_{\mathrm{B}}$ receptor (Xie and Smart, 1992a, b; King et al, 1997). This spontaneous activity appeared as rapidly rising inward currents at a frequency of $8.91 \pm 0.75 \mathrm{~Hz}$ and an amplitude of $28.1 \pm 2.4 \mathrm{pA} \quad(n=8)$. In this slice preparation, most synaptic drive to $\mathrm{SNc}$ dopaminergic neurons is GABAergic, since extrinsic glutamatergic afferents are lost, while the intrinsic GABAergic drive is preserved. Indeed, the spontaneous synaptic currents could be blocked by bicuculline ( $30 \mu \mathrm{M}$; Figure 1a), indicating that they were spontaneous inhibitory synaptic currents (sIPSCs) mediated by $\mathrm{GABA}_{\mathrm{A}}$ receptors.

Bath application of GHB $(600 \mu \mathrm{M})$ reduced sIPSCs frequency to $5.46 \pm 0.58 \mathrm{~Hz} \quad(-38.7 \pm 6.5 \% ; \quad \mathrm{F}=25.5$, $p<0.01)$ and sIPSCs amplitude to $21.4 \pm 2.2 \mathrm{pA}$ $(-23.8 \pm 7.8 \% ; \mathrm{F}=28.1, p<0.01 ; n=8$; Figure $1 \mathrm{~b}-\mathrm{e})$. After $10 \mathrm{~min}$ GHB washout, sIPSCs frequency recovered to 

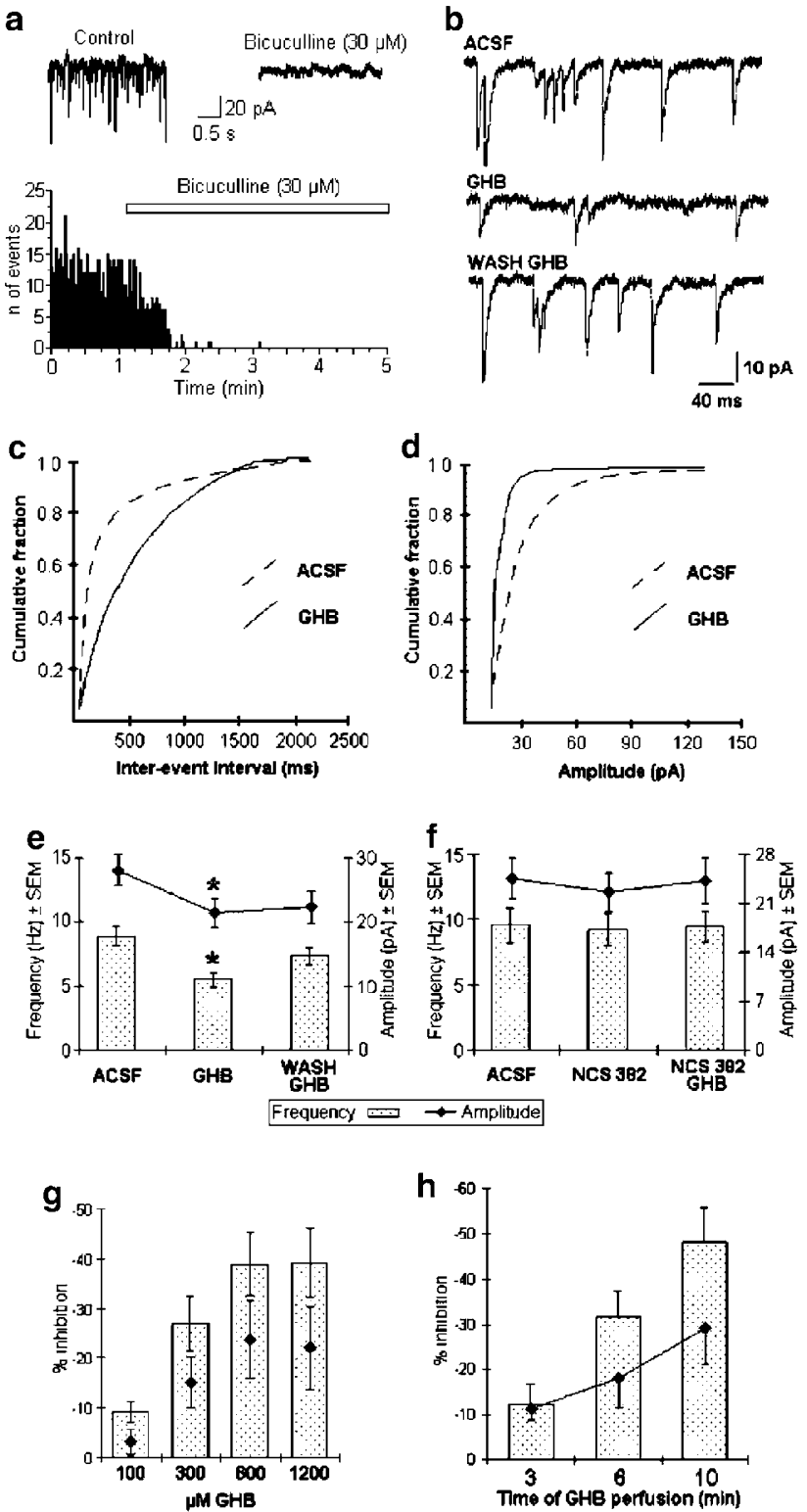

Figure I Effects of GHB on sIPSCs. (a) Bicuculline blocked sIPSCs, indicating that they are $\mathrm{GABA}_{\mathrm{A}}$-dependent. Top: recordings of sIPSC in control (ACSF) and during bicuculline $(30 \mu \mathrm{M})$ perfusion in a representative neuron. Bottom: histogram showing the number of events recorded from the same neuron in control (ACSF) and during bicuculline perfusion. (b) Recordings of sIPSC in control, during GHB $(600 \mu \mathrm{M})$ perfusion, and upon washout of GHB in a representative neuron. (c) Cumulative interevent interval distribution of a representative cell, revealing a significant increase in the interevent interval (ie decreased frequency) during GHB application. (d) Cumulative amplitude distribution obtained from the same cell reveals a significant decrease in sIPSC amplitude during GHB application. (e) Summary of the mean effect of GHB on the frequency and amplitude of the sIPSCs. Significant reductions $(*)$ were observed in both frequency and amplitude $(n=8)$. (f) NCS 382, an antagonist of GHB receptors, blocks the effects of GHB on sIPSCs. Application of NCS $382(500 \mu \mathrm{M})$ alone showed no effects but blocked the effects of GHB $(600 \mu \mathrm{M})$ on both frequency and amplitude $(n=4)$. (g) GHB reduction of sIPSCs frequency and amplitude at concentrations of $100 \mu \mathrm{M}(n=6), 300 \mu \mathrm{M}(n=7), 600 \mu \mathrm{M}(n=8)$, and $1200 \mu \mathrm{M}(n=8)$. Data are percentage inhibition of frequency and amplitude $( \pm$ SEM). Maximal reduction was seen at GHB concentrations of $600-1200 \mu \mathrm{M}$. Therefore, a GHB concentration of $600 \mu \mathrm{M}$ was used for the study. (h) Time course of the effect of GHB $(600 \mu \mathrm{M})$. Chart shows percentage inhibition of frequency and amplitude ( \pm SEM) observed 3, 6, and 10 min after GHB application.
$7.36 \pm 0.66 \mathrm{~Hz}$ and sIPSCs amplitude to $22.3 \pm 2.6 \mathrm{pA}$. To investigate the dose-response relationship, we further tested the effects of GHB at 100,300 , and $1200 \mu \mathrm{M}$. GHB $(100 \mu \mathrm{M})$ reduced mean sIPSC frequency from $4.44 \pm 1.55$ to $4.03 \pm 1.89 \mathrm{~Hz}(-9.2 \pm 2.2 \% ; \mathrm{F}=0.564, p=0.486)$ and mean sIPSC amplitude from $21.26 \pm 5.65$ to $20.59 \pm 6.56 \mathrm{pA}$ $(-3.2 \pm 2.7 \% ; \mathrm{F}=0.609, p=0.470 ; n=6)$. GHB $(300 \mu \mathrm{M})$ exerted a significant reduction of sIPSC mean frequency from $5.67 \pm 1.68$ to $4.14 \pm 1.33 \mathrm{~Hz} \quad(-26.9 \pm 5.5 \%$; $\mathrm{F}=10.34, p=0.018)$ and mean sIPSC amplitude from $22.11 \pm 4.75$ to $18.76 \pm 6.56 \mathrm{pA} \quad(-15.1 \pm 5.1 \% ; \mathrm{F}=9.78$, $p=0.020 ; n=7)$. Finally, GHB $(1200 \mu \mathrm{M})$ exerted a significant reduction of SIPSC mean frequency from $5.55 \pm 1.59$ to $3.38 \pm 1.21 \mathrm{~Hz} \quad(-39.0 \pm 7.1 \% ; \mathrm{F}=12.53$, $p=0.009)$ and mean sIPSC amplitude from $22.32 \pm 5.12$ to $17.38 \pm 4.83 \mathrm{pA}(-22.1 \pm 8.3 \% ; \mathrm{F}=6.29, p=0.041 ; n=8$; Figure $1 \mathrm{~g}$ ). Cumulative interevent interval and amplitude distributions were significantly different between control and GHB $(p<0.01$, KS test) in six out of eight cells tested. Analysis of the time course (Figure $1 \mathrm{~h}$ ) of the effect of GHB $(600 \mu \mathrm{M})$ showed that in the first $3 \mathrm{~min}$ of drug application, the mean reduction of the IPSCs was $-12.2 \pm 4.5 \%$ (frequency) and $-11.2 \pm 2.4 \%$ (amplitude). Within $6 \mathrm{~min}$ from GHB application, the reduction of IPSCs reached $-31.8 \pm 5.7 \%$ (frequency) and $-18.1 \pm 6.6 \%$ (amplitude), while at $10 \mathrm{~min}$ the reduction of the IPSCs reached a steadystate level of $-38.7 \pm 6.5 \%$ (frequency) and $-23.8 \pm 7.8 \%$ (amplitude). To characterize the receptors involved in GHBinduced effects, we repeated the experiments in the presence of the GHB antagonist NCS-382 $(500 \mu \mathrm{M})$. As shown in Figure 1f, NCS-382 $(500 \mu \mathrm{M})$ applied alone for $15 \mathrm{~min}$ had no significant effect on the frequency (from $9.55 \pm 1.33$ to $9.25 \pm 1.22 \mathrm{~Hz}$ ) and amplitude (from $24.55 \pm 2.98$ to $22.62 \pm 2.84 \mathrm{pA}, n=4)$ of the sIPSCs. However, after $15 \mathrm{~min}$ of application of NCS-382 $(500 \mu \mathrm{M})$, this drug was able to block the effect of GHB $(600 \mu \mathrm{M}$, applied for $10 \mathrm{~min})$ on the frequency $(+3.14 \pm 12.77 \%$, $p>0.05)$ and amplitude $(+7.86 \pm 11.56 \%, p>0.05)$ of the sIPSCs.

These results indicate a depressive effect of GHB on sIPSCs in the SNc. Since both frequency and amplitude of sIPSCs were reduced by GHB, these observations suggest a reduced probability of GABA release or a reduced postsynaptic responsiveness to GABA. In order to discriminate between these two possibilities, we investigated the effects of GHB on action-potential-independent, miniature IPSCs (mIPSCs) recorded in the presence of the voltage-dependent $\mathrm{Na}^{+}$channel blocker TTX.

\section{Effects of GHB on Miniature IPSCs}

$\mathrm{GABA}_{\mathrm{A}}$-induced mIPSCs were recorded from dopaminergic neurons of the SNc in the presence of TTX $(1 \mu \mathrm{M})$ and the $\mathrm{GABA}_{\mathrm{B}}$ antagonist CGP 55845A $(1 \mu \mathrm{M})$. TTX alone reduced the sIPSCs frequency from $9.76 \pm 0.96$ to $1.34 \pm 0.16 \mathrm{~Hz}$ and the sIPSCs amplitude from $25.61 \pm 2.4$ to $23.3 \pm 2.2 \mathrm{pA}$ $(n=7)$. The frequency of mIPSCs during GHB $(600 \mu \mathrm{M})$ perfusion was $1.23 \pm 0.14 \mathrm{~Hz}$, and was not significantly different from controls $(\mathrm{F}=0.1, p>0.05)$. Similarly, mIPSCs amplitude with GHB was $22.9 \pm 1.9 \mathrm{pA}$, and the difference from controls was not significant $(\mathrm{F}=0.3, p>0.05)$ (Figure 2). Interevent interval and amplitude distributions 
a

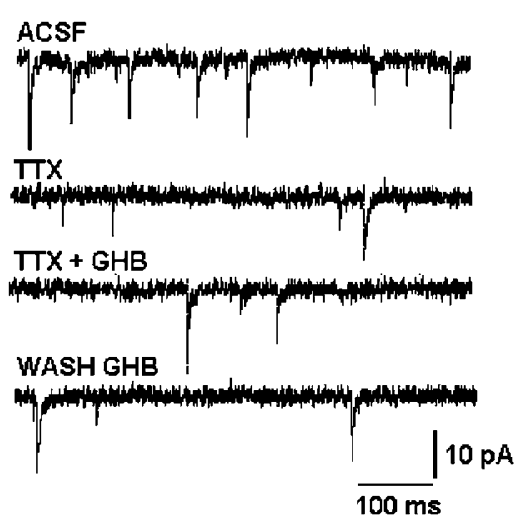

b $\rightleftharpoons$ Frequency $\rightarrow$ Amplitude

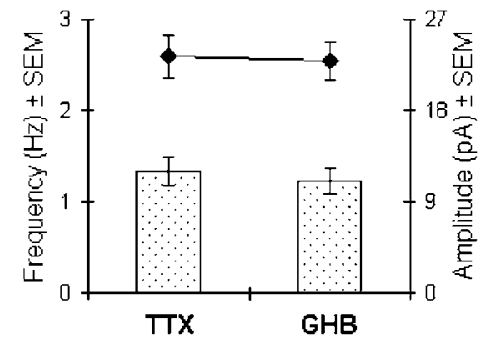

C

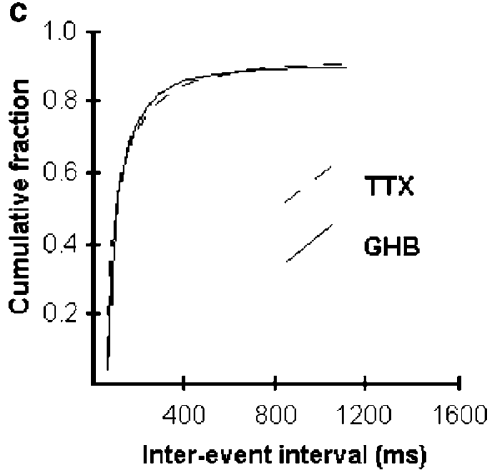

d

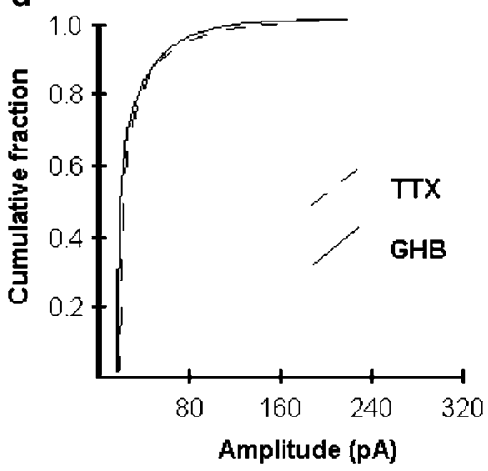

Figure 2 Effects of GHB on mIPSCs. (a) Traces representing recordings of mIPSCs in ACSF, in the presence of TTX $(\mathrm{I} \mu \mathrm{M})$, during GHB $(600 \mu \mathrm{M})$ perfusion, and during $\mathrm{GHB}$ washout in one representative neuron. (b) Mean effect of GHB $(600 \mu \mathrm{M})$ on the frequency and amplitude of the mIPSCs. No effects were observed in both frequency and amplitude $(n=7)$. (c) Cumulative interevent interval distribution of a representative cell, revealing no changes in mIPSC frequency during application of GHB $(600 \mu \mathrm{M})$. (d) Cumulative amplitude distribution obtained from the same cell revealing no changes in mIPSCs amplitude during application of GHB $(600 \mu \mathrm{M})$.

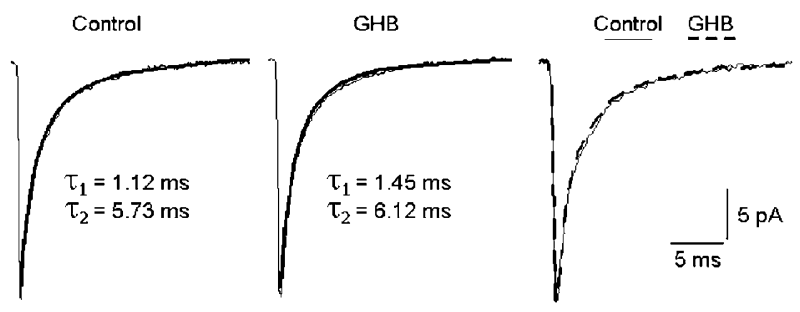

Figure 3 Averages of $200 \mathrm{mIPSCs}$ recorded (left) in control (TTX, I $\mu \mathrm{M})$ and (middle) during GHB $(600 \mu \mathrm{M})$ application (representative cell) Traces are fit with a double exponential function. Statistical analysis of $\tau_{1}$ and $\tau_{2}$ showed that there were no significant differences in the mIPSCs kinetics between TTX (control) and GHB. Right: control and GHB mean mIPSCs are superimposed.

were not significantly different in the controls and in the GHB ( $p>0.05, n=7$, KS test).

We also analyzed the kinetics of these miniature events $(n=7)$, by fitting the decay phase of the averaged mIPSCs with a double exponential function, in control and in GHB for each cell. GHB showed no effects on $\tau_{1}$ (from $1.21 \pm 0.56$ to $1.57 \pm 0.84 \mathrm{~ms}, p=0.61, n=7$, ANOVA test) nor on $\tau_{2}$ (from $5.71 \pm 2.83$ to $5.98 \pm 1.92 \mathrm{~ms}, p=0.63, n=7$, ANOVA test; Figure 3).

These experiments on mIPSCs demonstrate that, when voltage-dependent $\mathrm{Na}^{+}$channels are blocked, the depressive effect of GHB on frequency and amplitude of sIPSCs is suppressed. Thus, GHB does not reduce postsynaptic responsiveness to GABA, and GHB may have an effect at a presynaptic site. The observation that mIPSCs frequency was unaffected by GHB also suggests that the depressing action of this compound on sIPSCs may be ascribed either to a direct action on voltage-dependent $\mathrm{Na}^{+}$channels or to a reduction of voltage-dependent calcium conductances activated following the $\mathrm{Na}^{+}$channel-induced depolarization. To discern between these possibilities, we examined the actions of GHB on mIPSCs recorded in the presence of high extracellular potassium $\left(15 \mathrm{mM}\left[\mathrm{K}^{+}\right]_{0}\right)$ in order to promote the release of GABA through an artificial depolarization of the presynaptic terminal.

\section{Effects of GHB on mIPSCs during Depolarization with $\mathrm{KCl}$}

In the presence of TTX $(1 \mu \mathrm{M})$, the elevation of extracellular $\mathrm{K}^{+}$from 3 to $15 \mathrm{mM}$ produced a significant increase in both mIPSCs frequency (from $0.91 \pm 0.12$ to $1.35 \pm 0.19 \mathrm{~Hz}$; $n=9 ; \quad p<0.05$ ) and amplitude (from $13.8 \pm 0.33$ to $18.5 \pm 0.35 \mathrm{pA} ; n=9, \quad p<0.05)$. To confirm that the increased frequency and amplitude of mIPSCs observed in high $\left[\mathrm{K}^{+}\right]_{0}$ was due to voltage-dependent calcium channel activation, we applied $\mathrm{CdCl}_{2}(200 \mu \mathrm{M})$ in three neurons. In these cells, $\mathrm{CdCl}_{2}$ reduced the frequency to $0.88 \pm 0.51 \mathrm{~Hz}$ and amplitude to $12.9 \pm 1.1 \mathrm{pA}$, values not statistically different from those recorded in the presence of TTX alone ( $p>0.05$ for frequency and amplitude).

Under conditions of elevated $\left[\mathrm{K}^{+}\right]_{0}$, perfusion of $\mathrm{GHB}$ $(600 \mu \mathrm{M})$ significantly reduced the frequency of mIPSCs to $0.84 \pm 0.20 \mathrm{~Hz}(-37.8 \pm 5.2 \% ; p<0.05)$ while their amplitude was not affected $(16.8 \pm 2.8 \mathrm{pA} ; p>0.05)$. Upon GHB washout, mIPSCs frequency recovered to control levels 
a
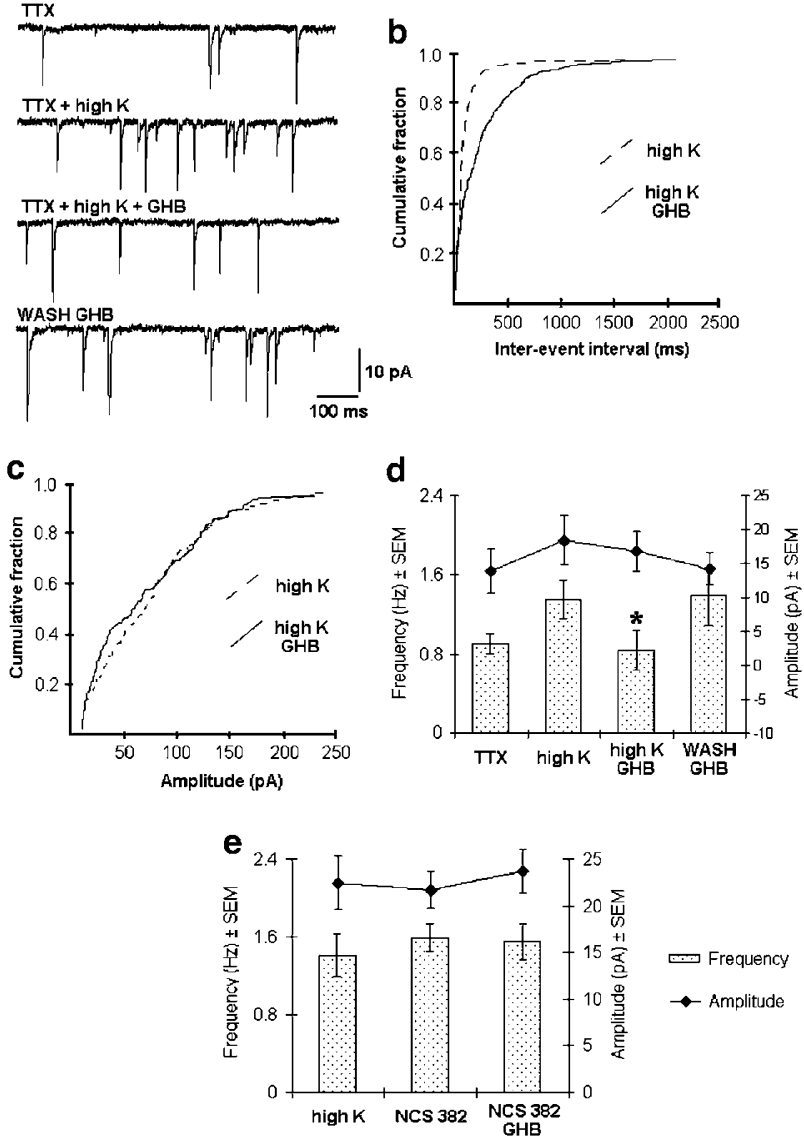

Figure 4 Effects of GHB on mIPSCs recorded in elevated $\left[\mathrm{K}^{+}\right]_{0}$. (a) Recordings of mIPSCs in TTX $(I \mu M)$, TTX $(I \mu M)$, and elevated $\left[K^{+}\right]_{0}$ ( $15 \mathrm{mM})$, during GHB $(600 \mu \mathrm{M})$ application and upon washout of GHB. (b) Cumulative interevent interval distribution of a representative cell, revealing a significant reduction of the mIPSCs frequency during GHB application. (c) Cumulative amplitude distribution obtained from the same cell revealing no changes in mIPSC amplitude during GHB $(600 \mu \mathrm{M})$ application. (d) Summary of the mean effect of GHB on the frequency and amplitude of the mIPSCs recorded in elevated $\left[\mathrm{K}^{+}\right]_{0}$. GHB reduced the frequency $(*)$ but not the amplitude of the mIPSCs $(n=9)$. (e) NCS 382 blocked the effect of GHB on the frequency of the mIPSCs recorded during elevated $\left[\mathrm{K}^{+}\right]_{0}(\mathrm{I} 5 \mathrm{mM})$. NCS 382 showed no effects per se on the frequency and amplitude of the mIPSCs $(n=3)$.

$(1.39 \pm 0.29 \mathrm{~Hz}, p>0.05)$. Cumulative interevent interval distributions in control and GHB were significantly different ( $p>0.05$, KS test) (Figure $4 a-d)$.

The specificity of the effect of GHB in high $\left[\mathrm{K}^{+}\right]_{0}$ was tested by repeating the same experiments in the presence of the GHB receptor antagonist NCS-382. As shown in Figure 4e, NCS-382 $(500 \mu \mathrm{M})$ applied alone for $10 \mathrm{~min}$ had no significant effect on the frequency (from $1.41 \pm 0.22$ to $1.59 \pm 0.14 \mathrm{~Hz}, p>0.05$ ) and amplitude (from $22.45 \pm 2.88$ to $21.72 \pm 1.99 \mathrm{pA}, n=3$ ) of the mIPSCs. However, NCS-382 $(500 \mu \mathrm{M})$ prevented the effect of GHB $(600 \mu \mathrm{M})$ on the frequency $(-1.95 \pm 2.71 \%, p>0.05)$ of the mIPSCs.

These results show that, although there is no direct evidence of an action of GHB on voltage-dependent calcium channels, the depression effect of GHB on the frequency of mIPSCs is most likely due to its action on presynaptic voltage-dependent calcium influx activated following action potential invasion of the presynaptic terminal.

\section{DISCUSSION}

The present study demonstrates that GHB reversibly reduces both frequency and amplitude of sIPSCs in dopaminergic neurons of the $\mathrm{SNc}$, following a reduction of GABA release, most likely due to inhibition of calcium influx in the presynaptic terminal.

The concentrations of GHB used in this study (100$1200 \mu \mathrm{M}$ ) are in the range of those measured in the rat brain after systemic administration of pharmacologically effective doses $(200-400 \mathrm{mg} / \mathrm{kg})$ that reduced voluntary alcohol intake (Fadda et al, 1988). Moreover, the dose-response relationship (Figure 1g) and previous reports showed maximal and specific action of GHB at the concentration of $600 \mu \mathrm{M}$ (Berton et al, 1999; Cammalleri et al, 2002). It should be noted that previous studies (Madden and Johnson, 1998; Erhardt et al, 1998; Shepard and Connelly, 1999) reported an inhibitory effect of GHB on nigral dopamine neurons. However, higher doses of GHB were used by these authors, and no $\mathrm{GABA}_{\mathrm{B}}$ receptor antagonist was present in the perfusing medium. Conversely, the continuous presence of CGP 55845A in our work prevented $\mathrm{GABA}_{\mathrm{B}}$ receptor activation by GHB and we never observed changes in the holding current or in cell input resistance such as those reported by other authors (see also Olpe and Koella, 1979; Kozhechkin, 1980; Xie and Smart, 1992a).

The action of GHB can be at least in part ascribed to specific depressing mechanisms, since the reduction of sIPSCs frequency and amplitude by GHB was prevented by NCS-382, a GHB receptor antagonist (Maitre et al, 1990). This result suggests that the depressant effect of GHB shown in this study, which leaves out GHB effects on the $G_{A B A}$ receptor, is mediated by the activation of the GHB receptor. In this regard, it should be mentioned that the selectivity and specificity of NCS-382 for the GHB receptor is still a matter of debate, as some laboratories have reported divergent results regarding this issue (Metcalf et al, 2001; Carter et al, 2003; Gould et al, 2003; Lamb et al, 2003).

A GHB-induced depression of the spontaneous inhibitory synaptic transmission has been reported previously in neocortical neurons (Jensen and Mody, 2001). This depression was obtained at higher concentrations $(10 \mathrm{mM})$ than those of the present study and it was reversibly blocked by a selective $\mathrm{GABA}_{\mathrm{B}}$ antagonist. Thus, GHB can also activate presynaptic $G_{A B A}$ receptors to reduce inhibitory and excitatory transmitter release as described in other reports (Xie and Smart, 1992a, b; King et al, 1997). In the presence of TTX $(1 \mu \mathrm{M})$, no reduction in mIPSCs amplitude and frequency was observed indicating that the depressing effect of GHB on sIPSCs was not due to a reduced postsynaptic sensitivity to GABA but to a presynaptic depression of GABA release. Our observation that GHB did not alter the kinetic properties of mIPSCs contradicts its postsynaptic mechanism of action. Moreover, the observation that $\mathrm{K}^{+}$evoked release of GABA was attenuated by GHB also implies a presynaptic mechanism of action (Banerjee and Snead, 1995). Additionally, it has been previously shown that GHB receptors are found mostly on nerve terminals (Maitre et al, 1983). A presynaptic mechanism of action of GHB has also been proposed in the hippocampus in experiments on paired pulse facilitation (Berton et al, 1999) or following exogenous application of GABA (Cammalleri et al, 2002). 
A presynaptic mechanism underlying the effect of GHB does not conflict with the observed reduction of sIPSCs amplitude. A conceivable explanation for this result is the presence of multiple release sites on the GABAergic terminals that simultaneously release GABA when invaded by an action potential. Thus, a presynaptic depression of action-potential-driven events would result in the suppression of higher amplitude multiquantal events. In agreement with this hypothesis, perfusion with TTX also resulted in reduction of both frequency and amplitude of spontaneous synaptic events.

The lack of effect in the presence of TTX indicates that GHB only depresses synaptic GABAergic events triggered by action potentials. Hence GHB may affect the action potential itself by inhibiting its generation or its ability to invade the terminal. However, GHB may also reduce the calcium influx, following spike-driven activation of voltagegated calcium channels. In order to discriminate between these possibilities, we bypassed the possible effects on action potentials by performing experiments in the presence of TTX and then depolarizing the terminals with high extracellular $\mathrm{K}^{+}(15 \mathrm{mM})$. In this condition, we were able to promote a cadmium-sensitive increase in MIPSC frequency, indicating an increased GABAergic neurotransmission due to calcium channel activation independent of spike generation. In these conditions, the ability of GHB to reduce sIPSC frequency was restored. This result gives a strong indication that voltage-dependent calcium entry could be a specific target of GHB action, whereby spontaneous synaptic GABAergic release could be inhibited by reducing the spike-dependent calcium influx into the terminal.

The inhibitory effect of GHB on GABAergic neurotransmission reported here is expected to have substantial influences on the activity of the dopaminergic neurons of the ventral midbrain, and consequently on a wide range of behaviors related to drug abuse.

\section{ACKNOWLEDGEMENTS}

We thank P Schweitzer for critical comments on the manuscript.

\section{REFERENCES}

Addolorato G, Cibin M, Caprista E, Beghe F, Gessa GL, Stefanini GF et al (1998). Maintaining abstinence from alcohol with gamma-hydroxybutyric acid. Lancet 351: 38.

Banerjee PK, Snead OC (1995). Presynaptic gamma-hydroxybutyric acid and gamma-aminobutyric acid B receptor-mediated release of GABA and glutamate in rat thalamic ventrobasal nucleus: a possible mechanism for the generation of absence-like seizures induced by gamma-hydroxybutyric acid. J Pharmacol Exp Ther 273: 1534-1543.

Benavides J, Rumigny JF, Bourguignon JJ, Cash C, Wermuth CG, Mandel P et al (1982). High affinity binding sites for gammahydroxybutyric acid in rat brain. Life Sci 30: 953-961.

Bernasconi R, Mathivet P, Marescaux C (1999). Gamma-hydroxybutyric acid: an endogenous neuromodulator with abuse potential? Trends Pharmacol Sci 20: 135-141.

Berton F, Brancucci A, Beghè F, Cammalleri M, Demuro A, Francesconi W et al (1999). Gamma-hydroxybutyrate inhibits excitatory postsynaptic potentials in rat hippocampal slices. Eur J Pharmacol 380: 109-116.
Bessman SP, Fishbein WN (1963). Gamma-hydroxybutyrate, a normal brain metabolite. Nature 200: 1207-1208.

Bolam JP, Smith Y (1990). The GABA and substance P input to dopaminergic neurones in the substantia nigra of the rat. Brain Res 529: 57-78.

Bunney BS, Chiodo LA, Grace AA (1991). Midbrain dopamine system electrophysiological functioning: a review and new hypothesis. Synapse 9: 79-94 (review).

Cammalleri M, Brancucci A, Berton F, Locche A, Gessa GL, Francesconi W (2002). Gamma-hydroxybutyric acid reduces GABA-mediated inhibitory postsynaptic potentials in the CA1 region of hippocampus. Neuropsychopharmacology 27: 960-969.

Carter LP, Flores LR, Wu H, Chen W, Unzeitig AW, Coop A et al (2003). The role of GABAB receptors in the discriminative stimulus effects of gamma-hydroxybutyrate in rats: time course and antagonism studies. J Pharmacol Exp Ther 305: 668-674.

Castelli MP, Mocci I, Langlois X, Gommerendagger W, Luyten WH, Leysen JE et al (2000). Quantitative autoradiographic distribution of gamma-hydroxybutyric acid binding sites in human and monkey brain. Brain Res Mol Brain Res 78: 91-99.

Chen BT, Rice ME (2002). Synaptic regulation of somatodendritic dopamine release by glutamate and GABA differs between substantia nigra and ventral tegmental area. J Neurochem 81: 158-169.

Diana M, Mereu G, Mura A, Fadda F, Passino N, Gessa G (1991). Low doses of gamma-hydroxybutyric acid stimulate the firing rate of dopaminergic neurons in unanesthetized rats. Brain Res 566: 208-211.

Erhardt S, Andersson B, Nissbrandt H, Engberg G (1998). Inhibition of firing rate and changes in the firing pattern of nigral dopamine neurons by gamma-hydroxybutyric acid (GHBA) are specifically induced by activation of GABA(B) receptors. Naunyn Schmiedebergs Arch Pharmacol 357: 611-619.

Fadda F, Mosca GL, Colombo G, Gessa GL (1988). Gammahydroxybutyric acid suppresses ethanol consumption in alcoholpreferring rats. Psychopharmacology 96(Suppl): 107.

Fasano S, Brambilla R (2002). Cellular mechanisms of striatumdependent behavioral plasticity and drug addiction. Curr Mol Med 2: 649-665.

Galloway GP, Frederick SL, Staggers Jr FE, Gonzalez M, Stalcup A, Smith DE (1997). Gamma-hydroxybutyrate: an emerging drug of abuse that causes physical dependence. Addiction 92: 89-96.

Gould GG, Mehta AK, Frazer A, Ticku MK (2003). Quantitative autoradiographic analysis of the new radioligand $[(3) H](2 \mathrm{E})-(5-$ hydroxy-5,7,8,9-tetrahydro-6H-benzo[a][7] annulen-6-ylidene) ethanoic acid ([(3)H]NCS-382) at gamma-hydroxybutyric acid (GHB) binding sites in rat brain. Brain Res 979: 51-56.

Grace AA, Bunney BS (1983). Intracellular and extracellular electrophysiology of nigral dopaminergic neurons - 1. Identification and characterization. Neuroscience 10: 301-315.

Hausser MA, Yung WH (1994). Inhibitory synaptic potentials in guinea-pig substantia nigra dopamine neurones in vitro. J Physiol 479: 401-422.

Hechler V, Gobaille S, Bourguignon JJ, Maitre M (1991). Extracellular events induced by gamma-hydroxybutyrate in striatum: a microdialysis study. J Neurochem 56: 938-944.

Hechler V, Gobaille S, Maitre M (1992). Selective distribution pattern of gamma-hydroxybutyrate receptors in the rat forebrain and midbrain as revealed by quantitative autoradiography. Brain Res 572: 345-348.

Hechler V, Weissmann D, Mach E, Pujol JF, Maitre M (1987). Regional distribution of high-affinity gamma-[3H]hydroxybutyrate binding sites as determined by quantitative autoradiography. J Neurochem 49: 1025-1032.

Hedou G, Chasserot-Golaz S, Kemmel V, Gobaille S, Roussel G, Artault JC et al (2000). Immunohistochemical studies of the 
localization of neurons containing the enzyme that synthesizes dopamine, GABA, or gammahydroxybutyrate in the rat substantia nigra and striatum. J Comp Neurol 426: 549-560.

$\mathrm{Hu}$ RQ, Banerjee PK, Snead III OC (2000). Regulation of gamma-aminobutyric acid release in cerebral cortex in the gamma-hydroxybutyric acid model of absence seizures in rat. Neuropharmacology 39: 427-439.

Hyman SE, Malenka RC (2001). Addiction and the brain: the neurobiology of compulsion and its persistence. Nat Rev Neurosci 2: 695-703 (review).

Jensen K, Mody I (2001). GHB depresses fast excitatory and inhibitory synaptic transmission via $\mathrm{GABA}_{B}$ receptors in mouse neocortical neurons. Cerebral Cortex 11: 424-429.

King MA, Thinschmidt JS, Walker DW (1997). Gamma-hydroxybutyrate receptor ligand effects on evoked synaptic field potentials in CA1 of the rat hippocampal slice. J Neural Transm 104: 1177-1193.

Kleinschmidt S, Scellhase C, Martzluft F (1999). Continous sedation during spinal anaesthesia: gamma-hydroxybutyrate $v \mathrm{~s}$ propofol. Eur J Anaesthesiol 16: 23-30.

Kozhechkin SX (1980). Microiontophoretic study of the mechanism of action of gamma-hydroxybutyric acid. Bull Exp Biol Med 88: $1293-1296$

Lamb RJ, Munn J, Duiker NJ, Coop A, Wu H, Koek W et al (2003). Interactions of gamma-hydroxybutyrate with ethanol and NCS 382. Eur J Pharmacol 470: 157-162.

Madden TE, Johnson SW (1998). Gamma-hydroxybutyrate is a $\mathrm{GABAB}$ receptor agonist that increases a potassium conductance in rat ventral tegmental dopamine neurons. J Pharmacol Exp Ther 287: 261-265.

Maharajan P, Maharajan V, Ravagnan G, Paino G (2001). The weaver mutant mouse: a model to study the ontogeny of dopamine transmission systems and their role in drug addiction. Prog Neurobiol 64: 269-276 (review).

Maitre M (1997). The gamma-hydroxybutyrate signalling system in the brain: organization and functional implications. Prog Neurobiol 51: 337-361.

Maitre M, Hechler V, Vayer P, Gobaille S, Cash CD, Schmitt M et al (1990). A specific gamma-hydroxybutyrate receptor ligand possesses both antagonistic and anticonvulsant properties. J Pharmacol Exp Ther 255: 657-663.

Maitre M, Rumigny JF, Cash C, Mandel P (1983). Subcellular distribution of gamma-hydroxybutyrate binding sites in rat brain. Principal location in the synaptosomal fraction. Biochem Biophys Res Commun 110: 262-265.

Mamelak M, Scharf MB, Woods M (1986). Treatment of narcolepsy with gamma-hydroxybutyrate. A review of clinical and sleep laboratory findings. Sleep 9: 285-289.
Mercuri NB, Bonci A, Calabresi P, Stratta F, Bernardi G (1995). Properties of the hyperpolarization-activated cation current Ih in rat midbrain dopaminergic neurons. Eur J Neurosci 7: $462-469$.

Metcalf BR, Stahl JM, Allen JD, Woolfolk DR, Soto PL (2001). Discrimination of gamma-hydroxybutyrate and ethanol administered separately and as a mixture in rats. Pharmacol Biochem Behav 70: 31-41.

Nissbrandt H, Elverfors A, Engberg G (1994). Pharmacologically induced cessation of burst activity in nigral dopamine neurons: significance for the terminal dopamine efflux. Synapse 17: 217-224.

Olpe HR, Koella WP (1979). Inhibition of nigral and neocortical cells by gamma-hydroxybutyrate: a microiontophoretic investigation. Eur J Pharmacol 53: 359-364.

Paladini CA, Celada P, Tepper JM (1999). Striatal, pallidal, and pars reticulata evoked inhibition of nigrostriatal dopaminergic neurons is mediated by GABA(A) receptors in vivo. Neuroscience 89: 799-812.

Poldrugo F, Addolorato G (1999). The role of gamma-hydroxybutyric acid in the treatment of alcoholism: from animal to clinical studies. Alcohol Alcohol 34: 15-24.

Roth RH, Giarman NJ (1969). Conversion of gamma-aminobutyric acid to gamma-hydroxybutyric acid in the rat. Biochem Pharmacol 19: 3001-3012.

Shepard PD, Connelly ST (1999). Pertussis toxin lesions of the rat substantia nigra block the inhibitory effects of the gammahydroxybutyrate agent, S(-)HA-966 without affecting the basal firing properties of dopamine neurons. Neuropsychopharmacology 21: 650-661.

Smith AD, Bolam JP (1990). The neural network of the basal ganglia as revealed by the study of synaptic connections of identified neurones. Trends Neurosci 13: 259-265 (review).

Smith Y, Charara A, Parent A (1996). Synaptic innervation of midbrain dopaminergic neurons by glutamate-enriched terminals in the squirrel monkey. J Comp Neurol 364: 231-253.

Snead III OC (2000). Evidence for a G protein-coupled gammahydroxybutyric acid receptor. J Neurochem 75: 1986-1996.

Somogyi P, Bolam JP, Totterdell S, Smith AD (1981). Monosynaptic input from the nucleus accumbens - ventral striatum region to retrogradely labelled nigrostriatal neurones. Brain Res 217: 245-263.

Xie X, Smart TG (1992a). Gamma-hydroxybutyrate hyperpolarizes hippocampal neurons by activating $\mathrm{GABA}_{\mathrm{B}}$ receptors. Eur $J$ Pharmacol 212: 291-294.

Xie X, Smart TG (1992b). Gamma-hydroxybutyrate depresses monosynaptic excitatory and inhibitory postsynaptic potentials in rat hippocampal slices. Eur J Pharmacol 223: 193-196. 